\section{The prevalence of visual impairment and blindness in underserved rural areas: a crucial issue for future}

H Hashemi ${ }^{1,2}$, A Yekta ${ }^{3}$, E Jafarzadehpur ${ }^{2}$, A Doostdar ${ }^{4}, \mathrm{H}$ Ostadimoghaddam ${ }^{5}$ and M Khabazkhoob ${ }^{6}$

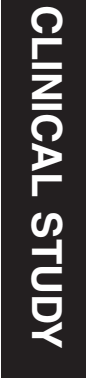

\begin{abstract}
Purpose To determine the prevalence of visual impairment and blindness in underserved Iranian villages and to identify the most common cause of visual impairment and blindness.

Patients and methods Multistage cluster sampling was used to select the participants who were then invited to undergo complete examinations. Optometric examinations including visual acuity, and refraction were performed for all individuals. Ophthalmic examinations included slit-lamp biomicroscopy and ophthalmoscopy. Visual impairment was determined according to the definitions of the WHO and presenting vision.
\end{abstract}

Results Of 3851 selected individuals, 3314 $(86.5 \%)$ participated in the study. After using the exclusion criteria, the present report was prepared based on the data of 3095

participants. The mean age of the participants was $37.6 \pm 20.7$ years (3-93 years). The prevalence of visual impairment and blindness was $6.43 \%$ (95\% confidence interval (CI): $3.71-9.14)$ and $1.18 \%$ (95\% CI: 0.56-1.79), respectively. The prevalence of visual impairment varied from $0.75 \%$ in participants aged less than 5 years to $38.36 \%$ in individuals above the age of 70 years. Uncorrected refractive errors and cataract were the first and second leading causes of visual impairment; moreover, cataract and refractive errors were responsible for $\mathbf{3 5 . 9 0}$ and $20.51 \%$ of the cases of blindness, respectively.

Conclusion The prevalence of visual impairment was markedly high in this study. Lack of access to health services was the main reason for the high prevalence of visual impairment in this study. Cataract and refractive errors are responsible for $80 \%$ of visual impairments which can be due to poverty in underserved villages.

Eye (2017) 31, 1221-1228; doi:10.1038/eye.2017.68; published online 21 April 2017

\section{Introduction}

Visual impairment is a major health challenge. ${ }^{1}$ Visual impairment is found in 285 million people worldwide of whom 39 are blind and 246 million have low vision. An important point mentioned by the WHO is the unequal distribution of visual impairment according to $\mathrm{WHO}$ regions. ${ }^{1}$ Visual impairment is responsible for 27.7 million disability-adjusted life years (DALY) which comprises $1.8 \%$ of the total DALY in the world. This disorder ranks 14th in the world and 11th in developing countries. It is estimated that it will rank 8 th in $2020\left(2.7 \%\right.$ of DALY). ${ }^{2}$ Uncorrected refractive error and cataract comprise $75 \%$ of the causes of visual impairment, which are all preventable ${ }^{1}$ Cataract is the leading cause of blindness in most low to moderate income countries ${ }^{1}$ while it has been replaced by macular degeneration and uncorrected refractive error in developed countries. ${ }^{3,4}$ Factors such as the socioeconomic status, geographic location, access to health services and resources, and having private insurance can affect visual impairment. ${ }^{5}$ Global rates of visual impairment have been reducing since the Vision 2020 Initiative was established by WHO coordinates throughout the world, especially in urban settings.

In rural areas, there is less access to health care services compared to urban areas due to bad road conditions and poverty. Recent studies have pointed to higher prevalence rates of visual impairment in rural areas on account of lack of
${ }^{1}$ Noor Research Center for Ophthalmic Epidemiology, Noor Eye Hospital, Tehran, Iran

${ }^{2}$ Noor Ophthalmology Research Center, Noor Eye Hospital, Tehran, Iran

${ }^{3}$ Department of Optometry, School of Paramedical Sciences, Mashhad University of Medical Sciences, Mashhad, Iran

${ }^{4}$ Department of Optometry, Iran University of Medical Sciences, Tehran, Iran

${ }^{5}$ Refractive Errors Research Center, School of

Paramedical Sciences, Mashhad University of Medical Sciences, Mashhad, Iran

${ }^{6}$ Department of Medical Surgical Nursing, School of Nursing and Midwifery, Shahid Beheshti University of Medical Sciences,

Tehran, Iran

Correspondence:

M Khabazkhoob,

Department of Medical

Surgical Nursing, School of Nursing and Midwifery, Shahid Beheshti University of Medical Sciences,

Tehran, Iran

Tel: +00 2182401615. Email: Khabazkhoob@ yahoo.com

Received: 27 May 2016 Accepted in revised form: 31 January 2017 Published online: 21 April 2017 
access to health care services (lack of cataract surgery). This is while a substantial proportion of the population in many countries resides in rural areas. The lower access rate is also responsible for the paucity of rural studies. A study on the rural population of Northen Iran showed that the higher prevalence of visual impairment and blindness could be addressed by enhancing facilities to support cataract surgery and provision of prescription eyeglasses to decrease the prevalence of visual impairment. ${ }^{6}$

In light of the importance of the prevalence of visual impairment among rural-dwellers, we conducted this study to evaluate the prevalence of blindness and visual impairment and their determinants in underserved villages of Iran.

\section{Materials and methods}

In this cross-sectional study, conducted in Iran from March 2015 to July 2015, the target population was underprivileged rural populations. The Rural Development Bureau within the presidential administration in the Islamic Republic of Iran provided us with the roster of deprived rural villages which we used as the sampling frame of the study. As a populationbased study, samples were selected from the residents of selected deprived villages in two provinces in Iran.

\section{Sampling method}

Sample selection was done through multistage cluster sampling. Using national data, two districts were randomly chosen from the north (Shahyoun a district of Dezful County, Khuzestan Province) and southwest (Kajour, a district of Noshhar County, Mazandaran Province) of the country. Then, a number of villages were randomly selected from the roster of each district.

Since we aimed to study visual impairment, the sample size was calculated based on the prevalence of visual impairment in a village in Iran. The sample size was 2267 for a rate of $6.3 \%$, a precision level of 0.01 , and a $95 \%$ confidence level. Considering the sampling method, a 1.5 design effect was applied, and then a $10 \%$ non-response rate was assumed which brought the final sample size to 3740 .

Sampling from each district was proportional to their total population with respect to the sample size. Thus, 15 villages in Shahyoun and 5 in Kajour were sampled to maintain the balance, because the villages in the former district were smaller and less populated. In each selected village, all over-one-year old residents were considered. In the selected households, all members over 1 year of age were invited to participate in the study, and an appointment date was fixed for their examinations.
To perform a pilot study, 35 people were tested for visual acuity and objective refraction by the two study optometrists. On the basis of the intraclass correlation coefficients, inter-examiner agreement was high (0.923 for uncorrected visual acuity and 0.897 for spherical equivalent refraction). All examinations were performed by these two optometrists who had a high agreement in detecting spherical refractive errors by retinoscopy and uncorrected visual acuity by a Snellen chart.

Examinations were conducted in one place under standard illumination conditions after obtaining informed consents from all participants and conducting an interview to collect certain demographic data. For those under 18 years, the consent was signed by the head of the household. Interviews were completed by a trained interviewer. Collected information included age, education level, the occupation of the head of the household, history of ocular surgery, history of eye problems, number of household members, smoking status, and systemic disease.

Optometric examinations were performed after the interview. First, refraction was measured using an auto refractometer (Nidek). Then, a Snellen chart at $6 \mathrm{~m}$ was used for visual acuity measurement. Lensometry was performed if the participant used glasses and the presenting visual acuity was recorded. All participants underwent retinoscopy using the results of auto refraction. If the visual acuity was not 20/20 in either eye, subjective refraction was performed. Then, all participants underwent slit-lamp biomicroscopy and of intraocular pressure measurement by an ophthalmologist before dilation. Then, cycloplegia was induced to perform cycloplegic refraction using cyclopentolate $1 \%$ in all individuals under 20 years. Cyclopentolate was instilled two times at a 5-minute interval and cycloplegic refraction was performed with an auto refractometer $35 \mathrm{~min}$ after the second instillation. The ophthalmologist completed the remainder of the examinations after dilation. These included grading clinical lens opacities, slit-lamp assessment of vitreous opacities, and the fundus exam with an ophthalmoscope.

\section{Definitions}

The WHO definition was used for visual impairment. Visual impairment included low vision and blindness and reported as presenting visual acuity (PVA). PVA is defined as uncorrected visual acuity for those who do not have corrective eyeglasses, and with current glasses for those who have them.

Low vision was defined as visual acuity between 0.5 $\operatorname{LogMAR}(20 / 60)$ and $\leq 1.3 \operatorname{LogMAR}(20 / 400)$ in the better eye. Blindness was defined as visual acuity worse than $1.3 \operatorname{LogMAR}(20 / 400)$ in the better eye. If a patient 
had several causes of visual impairment or each eye suffered different causes, the more correctable cause was considered as the cause of visual impairment.

\section{Statistical analysis}

The prevalence of visual impairment is reported as percentage with $95 \%$ confidence interval (CI) considering the design effect. Multiple logistic regression was used to detect the association between visual impairment and the study variables. Independent variables included in the logistic regression model included age, gender, education level, and place of residence. If the prevalence was low and the distribution was not normal, binomial distribution was used to calculate the $95 \%$ CI.

\section{Ethical issues}

The Ethics Committee of Tehran University of Medical Sciences approved the study protocol, which was conducted in accord with the tenets of the Helsinki Declaration. All participants signed a written informed consent.

\section{Results}

A total of 3851 individuals were selected through sampling of whom 3314 (86.5\%) participated in the study. Since visual acuity was not measured in 220 participants (lack of cooperation), analysis was performed on the data of 3095 individuals. Of them, 1747 (56.5\%) were female and the rest were male. The mean age of the participants was $37.6 \pm 20.7$ years (range: $3-93$ years). About $57.4 \%$ (1776 participants) lived in southern villages and the rest were from northern villages.

Table 1 shows the prevalence of visual impairment, blindness, and low vision by age, gender, educational level, and place of living.

The prevalence of visual impairment was 6.43\% (95\% CI: 3.71-9.14) with no significant difference between male and female participants. Its prevalence was $0 \%$ in individuals below the age of 5 years to $38.36 \%$ in individuals above the age of 70 years. The prevalence of visual impairment was $8.71 \%$ (95\% CI: 3.97-13.46) in the north and 4.37\% (95\% CI: 3.39-6.08) in the south of Iran $(P<0.00)$. The highest prevalence of visual impairment was observed in illiterate participants $(P<0.001)$.

Blindness was observed in $1.18 \%$ (95\% CI: $0.56-1.79)$ of the participants with no significant difference between male and female participants. The prevalence of blindness increased significantly with aging from $0.19 \%$ in individuals below the age of 5 years to $11.32 \%$ in participants aged 70 years and over. The highest prevalence of blindness was observed in illiterate participants and in northern villages.

A multiple logistic regression model was used to investigate the relationship of visual impairment and blindness with the study variables. The results showed that only age and education were significantly associated with visual impairment (Table 2).

According to Table 3, uncorrected refractive errors and cataract were the first and second cause of visual impairment; moreover, cataract, and refractive errors were responsible for 35.90 and $20.51 \%$ of the cases of blindness in our study.

\section{Discussion}

This population-based study was conducted to evaluate visual impairments in all age groups in the rural population of Iran. Rural areas comprise one third of the Iranian population. Increased migration of the young people, especially from underserved rural areas, to the cities has caused age inhomogeneity and therefore the population of rural areas is older than their urban counterparts, causing differences in their health needs. Considering the high prevalence of visual disorders in developing countries and the role of economic poverty on visual impairment, it was necessary to conduct this study in the rural population. ${ }^{7}$

According to a review of the literature presented in Table 4, the prevalence of visual impairment varies from 0.097 in Nepal to $30.5 \%$ in India. The prevalence of visual impairment in our study was in the middle of the reported ranges but the differences in the study populations and the inclusion and exclusion criteria should be considered before any comparison is made.

In addition to age groups, differences are seen between developed and developing countries; the prevalence of visual impairment in countries like Korea, Spain, and Iceland is much lower when compared with similar populations in developing countries like Libya, India, and Suriname. Studies performed in rural populations in India, Egypt, and China have shown a high prevalence of visual impairment in these countries, even higher than the prevalence of visual impairment in our study. Numerous studies have been performed on visual impairment in Iran but their results cannot be compared with the results of our study due to differences in the study population. Table 4, presents the studies conducted in Iran. The prevalence of visual impairment in our study was higher than Tehran and Shahroud studies but similar to studies performed in Zahedan, Sari, and villages in the north of Iran which all have a poor economic status.

Table 4, shows the prevalence of blindness in different parts of the world. The prevalence of blindness is $<1 \%$ in developed countries like Korea, Iceland, Spain, Australia, 
Table 1 The prevalence of visual impairment, blindness and low vision in underserved rural of Iran by gender, location of rural, age and educational level

\begin{tabular}{|c|c|c|c|c|}
\hline & $n(\%)$ & $\begin{array}{c}\text { Visual impairment } \\
\%(95 \% \text { CI })\end{array}$ & $\begin{array}{l}\text { Blindness } \\
\%(95 \% \text { CI) }\end{array}$ & $\begin{array}{l}\text { Low vision } \\
\%(95 \% \text { CI })\end{array}$ \\
\hline Total & 3095 (100) & $6.43(3.71-9.14)$ & $1.18(0.56-1.79)$ & $5.25(3.01-7.5)$ \\
\hline \multicolumn{5}{|l|}{ Gender } \\
\hline Female & $1747(56.5)$ & $6.34(2.96-9.71)$ & $1.2(0.54-1.87)$ & $5.13(2.17-8.1)$ \\
\hline Male & $1348(43.5)$ & $6.55(4.31-8.79)$ & $1.14(0.43-1.86)$ & $5.41(3.7-7.11)$ \\
\hline \multicolumn{5}{|l|}{ Age (years) } \\
\hline$\leq 5$ & $53(1.7)$ & 0 & 0 & 0 \\
\hline $6-20$ & $747(24.1)$ & $0.75(0.12-1.38)$ & $0.19(0.04-0.94)^{\mathrm{a}}$ & $0.56(0.15-2.09)^{\mathrm{a}}$ \\
\hline $21-30$ & $433(14)$ & $2.26(0.75-6.78)^{\mathrm{a}}$ & 0 & $2.27(0.75-6.87)^{\mathrm{a}}$ \\
\hline $31-40$ & $481(15.5)$ & $2.04(0.56-3.52)$ & $0.29(0.05-1.58)^{\mathrm{a}}$ & $1.75(0.62-4.93)^{\mathrm{a}}$ \\
\hline $41-50$ & 507 (16.4) & $2.76(1.38-4.14)$ & $0.55(0.15-2.07)^{\mathrm{a}}$ & $2.21(0.81-3.61)$ \\
\hline $51-60$ & 437 (14.1) & 7.05 (4.19-9.92) & $0.32(0.06-1.68)^{\mathrm{a}}$ & $6.73(4.18-9.28)$ \\
\hline $61-70$ & $213(6.9)$ & 20.39 (14.29-26.5) & $1.97(0.49-3.45)$ & 18.42 (11.93-24.92) \\
\hline$>70$ & $223(7.2)$ & $38.36(30-46.73)$ & $11.32(4.98-17.67)$ & $27.04(19.63-34.46)$ \\
\hline \multicolumn{5}{|l|}{ Education } \\
\hline Illiterate & $937(30.3)$ & $15.84(8.62-23.07)$ & $3.14(1.15-5.13)$ & $12.71(7.07-18.34)$ \\
\hline Primary school & $962(31.1)$ & $3.49(1.65-5.34)$ & $0.73(0.24-1.22)$ & $2.77(1.16-4.37)$ \\
\hline Guidance school & $345(11.1)$ & $1.63(0.5-2.75)$ & 0 & $1.63(0.5-2.75)$ \\
\hline High school & 607 (19.6) & $1.15(0.08-3.78)^{\mathrm{a}}$ & 0 & $1.15(0.37-2.68)^{\mathrm{a}}$ \\
\hline College & $244(7.9)$ & $1.72(0.03-3.58)^{\mathrm{a}}$ & 0 & $1.72(0.06-3.51)^{\mathrm{a}}$ \\
\hline \multicolumn{5}{|l|}{ Area } \\
\hline Southwest & 1776 (57.4) & $4.73(3.39-6.08)$ & $0.79(0.18-1.4)$ & $3.94(2.5-5.39)$ \\
\hline North & 1318 (42.6) & $8.71(3.97-13.46)$ & $1.7(0.69-2.72)$ & $7.01(3.29-10.74)$ \\
\hline
\end{tabular}

Abbreviation: CI, confidence interval. ${ }^{a}$ The $\mathrm{CI}$ was calculated by binomial distribution.

Table 2 Association between visual impairment with age, gender, education, and area

\begin{tabular}{lcc}
\hline & OR $(95 \%$ CI $)$ & P-value \\
\hline $\begin{array}{l}\text { Sex } \\
\quad \text { Male/female }\end{array}$ & $1.02(0.62-1.67)$ & 0.933 \\
Age & & \\
$\quad$ years & $1.07(1.05-1.09)$ & 0 \\
Education & & \\
$\quad$ Illiterate & 1 & 0.03 \\
Primary school & $0.66(0.45-0.95)$ & 0.006 \\
Guidance School & $0.35(0.17-0.7)$ & 0.005 \\
$\quad$ High school & $0.32(0.15-0.67)$ & 0.154 \\
College & $0.48(0.17-1.37)$ & 0.933 \\
Area (Southwest/north) & $1.02(0.62-1.67)$ & \\
\hline
\end{tabular}

Abbreviations: CI, confidence interval; OR, odds ratio.

and Poland, which is much lower than its prevalence in developing countries like Nepal, India, China, Nigeria, and Suriname. The prevalence of blindness is higher than $1 \%$ in most studies performed in developing countries.

The prevalence of blindness was $1.5 \%$ in our study, which is similar to the results of other developing countries and a study performed in villages in the north of Iran but
Table 3 Prevalence of different causes of visual impairment and blindness based on presenting visual acuity in the better eye

\begin{tabular}{|c|c|c|c|c|}
\hline & \multicolumn{2}{|c|}{$\begin{array}{l}\text { Visual } \\
\text { impairment }\end{array}$} & \multicolumn{2}{|c|}{ Blindness } \\
\hline & Number & $\%$ & Number & $\%$ \\
\hline Uncorrected refractive error & 108 & 54.27 & 8 & 20.51 \\
\hline Cataract & 54 & 27.14 & 14 & 35.90 \\
\hline Diabetic retinopathy & 9 & 4.52 & 3 & 7.69 \\
\hline $\begin{array}{l}\text { Age-related macular } \\
\text { degeneration }\end{array}$ & 7 & 3.52 & 3 & 7.69 \\
\hline Amblyopia & 4 & 2.01 & 1 & 2.56 \\
\hline Retinitis pigmentosa & 3 & 1.51 & 1 & 2.56 \\
\hline Albinism & 1 & 0.50 & 1 & 2.56 \\
\hline Corneal opacity & 2 & 1.01 & 0 & 0.00 \\
\hline Glaucoma & 3 & 1.51 & 2 & 5.13 \\
\hline Unknown & 8 & 4.02 & 3 & 7.69 \\
\hline Total & 199 & 100.0 & 36 & 92.31 \\
\hline
\end{tabular}

higher than local studies performed in Tehran, Shahroud, and Zahedan.

In our study, although the prevalence of visual impairment and blindness was a little higher in men than women, the difference was not significant. Some other studies have reported higher prevalence in women. 8,9 Factors such as the biological effects of female hormones 
Table 4 Prevalence of visual impairment, blindness, and causes of blindness reported in other studies according WHO definition

\begin{tabular}{|c|c|c|c|c|c|c|}
\hline Place & Sample size & Age & Criteria & $V I(\%)$ & Blindness (\%) & Causes of blindness \\
\hline China (Harbin) ${ }^{35}$ & 5057 & $50-96$ & WHO & 3.8 & 1.9 & Cataract, corneal opacity \\
\hline Hong Kong ${ }^{36}$ & 3441 & $\geq 60$ & WHO & 7.9 & 1.8 & Refractive errors, cataract \\
\hline Cameroon (Muyuka) 37 & 1787 & $\geq 40$ & WHO & 6.4 & 1.6 & Cataract, refractive errors \\
\hline Cameroon (Limbe) ${ }^{38}$ & 2215 & $\geq 40$ & WHO & 3 & 1.1 & Posterior segment disease, Cataract \\
\hline Iran $(\text { Sari })^{39}$ & 1185 & $\geq 55$ & WHO & 11.1 & 3.7 & Refractive errors, cataract \\
\hline Iran (Tehran) $)^{40}$ & 1074 & $40-59$ & WHO & 2.51 & 0.59 & Refractive errors, cataract \\
\hline Iran (Tehran) ${ }^{40}$ & 385 & $>60$ & WHO & 19.98 & 3.55 & NA \\
\hline Australia (Victoria) ${ }^{23}$ & 4744 & $\geq 40$ & WHO & 0.325 & 0.156 & AMD, glaucoma \\
\hline China (Beijing) ${ }^{41}$ & 5118 & $\geq 50$ & WHO & 8.38 & 1.27 & Cataract, retinal diseases \\
\hline China (Shanxi) ${ }^{42}$ & 75016 & $\geq 80$ & WHO & 0.4 & 0.2 & Cataract, retinopathy, and choroidopathy \\
\hline India (Urban) $)^{43}$ & 2421 & $>40$ & WHO & 10.2 & 1.2 & Cataract, uncorrected refractive error \\
\hline China (rural) ${ }^{44}$ & & $>40$ & WHO & 9.8 & 2.2 & Cataract, uncorrected refractive error \\
\hline $\mathrm{Nepal}^{45}$ & 10950 & $0-10$ & WHO & 0.079 & 0.068 & Amblyopia, cataract \\
\hline India (Andhra Pradesh) ${ }^{47}$ & 7281 & $\geq 50$ & WHO & 19.8 & 2.3 & cataract \\
\hline India (western coastal strip) ${ }^{48}$ & 2750 & $>50$ & WHO & 30.5 & 4.8 & Cataract, corneal scars, diabetic retinopathy \\
\hline Egypt (rural) $)^{49}$ & 600 & $\geq 40$ & WHO & 23.9 & 9.3 & $\begin{array}{l}\text { cataract, uncorrected refractive errors, } \\
\text { corneal opacities }\end{array}$ \\
\hline $\begin{array}{l}\text { Suriname (interior Maroon } \\
\text { population) })^{50}\end{array}$ & 586 & All & WHO & 17 & 4.4 & Cataract, glaucoma \\
\hline China (Guangdong) $)^{51}$ & 5531 & $\geq 50$ & WHO & 9.44 & 2.38 & Cataract \\
\hline China (Chongqing) 52 & 5663 & $\geq 50$ & WHO & 5.40 & 2.12 & Cataract \\
\hline Libya $^{53}$ & 8538 & $\geq 50$ & WHO & 21.7 & 3.25 & Cataract, glaucoma, other corneal scars \\
\hline India (Rural central) ${ }^{54}$ & 4711 & $>30$ & WHO & 7 & 0.5 & $\begin{array}{l}\text { Cataract, postoperative posterior capsular } \\
\text { opacification, }\end{array}$ \\
\hline Icelanders $^{55}$ & 1045 & $\geq 50$ & WHO & 1 & 0.6 & Amblyopia, cataract \\
\hline Iran (Shahroud) $)^{56}$ & 5190 & $40-64$ & WHO & 1.8 & 0.5 & $\begin{array}{l}\text { Uncorrected refractive errors, cataract, } \\
\text { amblyopia }\end{array}$ \\
\hline
\end{tabular}

or socioeconomic indexes with their effects on the access to or quality of the ophthalmic health services in women may result in differences between men and women, which requires regional studies. ${ }^{9}$

As mentioned in previous studies, we also found that the prevalence of visual impairment increased with aging. ${ }^{10,11}$ This increase in the prevalence is logical due to an increase in the factors affecting visual impairment. Aging and thinning of the macular tissue, lens opacity, cataract, diabetic retinopathy, and glaucoma, increase with age. ${ }^{12-14}$ About $65 \%$ of the visually impaired people are older than 50 years of age while they comprise $20 \%$ of the population. ${ }^{15}$ This point is very important in countries like Iran where the aging population is growing. Therefore, subsequent steps to decrease low vision and blindness should be aimed at older age groups.

In our study, cataract was identified as the leading cause of blindness, which is similar to other developed and developing countries. Table 4 , shows the causes of blindness according to different studies. Accordingly, cataract is the first cause of blindness in almost all developing countries. Poverty is associated with cataract and blindness. ${ }^{16}$ A study conducted in Pakistan showed that blindness was markedly more frequent in poor people. ${ }^{17}$ The prevalence of blindness in low income countries is five times higher than their high income counterparts in a global level. ${ }^{18}$ Cataract is responsible for $51 \%$ of the cases of blindness, that is, 20 million blind people. ${ }^{19}$ About $82 \%$ of the blind people are above 50 years of age; as a result, the global burden of blindness is increasing as the aging population is growing. ${ }^{15}$ If immediate measures are not devised and more resources are not allocated to confront blindness, the burden of blindness will double by $2020 .{ }^{19}$ In addition to the fact that blindness is more prevalent in poor people, blindness itself results in poverty in the affected person and those who have care for the blind person. ${ }^{20,21}$ Therefore, the poverty, cataract, and blindness have complex relationships which require more investigations in a global level. It is estimated that implementation of the Vision 2020 will result in the prevention of blindness in 429 million people and 102 billion dollars of economic benefit. $^{22}$

Refractive errors were the leading cause of visual impairment in our study, both in the younger and the older age groups. This finding is similar to other studies. ${ }^{23,24}$ Refractive errors are the first cause of visual impairment $(43 \%)$ and the second cause of blindness worldwide. ${ }^{1}$ According to the estimations of the $\mathrm{WHO}$, there are 153 million low vision and 5 million blind 
people in the world. ${ }^{25}$ A great proportion of uncorrected refractive errors occur in developing countries. ${ }^{26}$ Financial problems are a main barrier to the correction of refractive errors in different societies. ${ }^{27}$ A study conducted in European countries showed significant differences in the prevalence and causes of blindness and visual impairment between industrialized vs middle income countries. ${ }^{4}$ The same difference was observed in the evaluated provinces in our study as the prevalence of blindness and visual impairment and low vision was higher in the north $v s$ the south of the country (by about a factor of 2). According to a report published by Statistical Centre of Iran, the villagers residing in the south of Iran have a markedly higher income than their counterparts living in the north of Iran. The effect of economic factors on the prevalence of visual impairment is well established and it seems that in addition to other factors (private insurance, education, level, access to health services) economic variables play a major role in this regard. 5,28 A better economic status allows the population to use the health services provided by the private sector and affects their behavior regarding the utilization of public health services. People with a better economic status use primary health services more than the poor people. ${ }^{29}$ Moreover, many eye care services are offered in central and capital cities; as a result, those who can afford the travel costs use more services. Primary health services that are offered in rural areas cannot resolve blindness or visual impairment. These services are similar in the north and south of the country and therefore the difference in the prevalence of visual impairment and blindness between these regions is due to difference in the use of eye care services in other places.

In our study, a great proportion of visual impairment (81\%) and blindness (56.41\%) were due to uncorrected refractive errors and cataract, which are both preventable and correctable. Using glasses is an inexpensive way of correcting refractive errors in developing countries. ${ }^{30}$ Since people in rural areas can provide glasses with difficulty due to financial problems and accessibility issues, effective strategies should be designed to provide the rural population with low-cost corrective glasses. ${ }^{31}$

Moreover, offering cataract surgery services in rural areas can also markedly decrease the prevalence of blindness in the society. On the other hand, diabetic retinopathy alone was responsible for $4.52 \%$ of the cases of visual impairment and $7.69 \%$ of the cases of blindness. The prevalence of diabetes mellitus (both type 1 and type 2) is increasing in the world. Therefore, blindness and visual impairment due to diabetic retinopathy will be more prevalent in the coming years. ${ }^{32,33}$ A marked decrease in diabetic retinopathy related visual impairment can be achieved through screening and timely treatment. ${ }^{34}$ However, the capacity of the health system to confront the disease should be considered before screening. A study conducted by Hashemi et al in rural areas in the north of Iran showed that diagnostic facilities did not improve in rural areas in the past decades and these areas even lacked minimum facilities and equipment for the treatment of ocular problems. ${ }^{6}$ Availability of suitable diagnostic and therapeutic services or offering eye care services at least for older age groups are some appropriate measures to decrease the prevalence of visual disorders. These diagnostic and therapeutic procedures can be offered through health insurances.

\section{Summary}

\section{What was known before}

- Few studies have been performed on people residing in rural areas considering their lower access to health services. A study on the rural population of north of Iran showed a higher prevalence of blindness and visual impairment as compared to the urban population, and it seems to be health facilities like cataract surgery, and availability of glasses in villages can markedly decrease the prevalence of visual impairment With regards to the aforementioned and the necessity of the investigation of these visual problems in underserved rural population, we conducted this study to evaluate the prevalence of blindness and visual impairment and their determinants in underserved villages of Iran.

What this study adds

- Prevalence of visual impairment and blindness was markedly high in this study. Lack of access to health services was the main reason for the high prevalence of visual impairment in this study.

\section{Conflict of interest}

The authors declare no conflict of interest.

\section{Acknowledgements}

This project was supported by Iran National Science Foundation.

\section{References}

1 Pascolini D, Mariotti SP. Global estimates of visual impairment: 2010. Br J Ophthalmol 2011; 96(5): 614-618.

2 Candidate EAMP, Mahmoud Jabbarvand M, Sahar Sobhani M, Farzadfar F. National and sub-national burden of visual impairment in Iran 1990-2013; Study Protocol. Arch Iran Med 2014; 17(12): 810.

3 Bourne RR, Jonas JB, Flaxman SR, Keeffe J, Leasher J, Naidoo $\mathrm{K}$ et al. Prevalence and causes of vision loss in high-income countries and in Eastern and Central Europe: 1990-2010. Br J Ophthalmol 2014; 98(5): 629-638. 
4 Kocur I, Resnikoff S. Visual impairment and blindness in Europe and their prevention. Br J Ophthalmol 2002; 86(7): 716-722.

5 Livingston P, McCarty C, Taylor H. Visual impairment and socioeconomic factors. Br J Ophthalmol 1997; 81(7): 574-577.

6 Hashemi H, Rezvan F, Yekta A, Ostadimoghaddam H, Soroush S, Dadbin N et al. The prevalence and causes of visaual impairment and blindness in a rural population in the north of Iran. Iran J Public Health 2015; 44(6): 855-864.

7 Tielsch JM, Sommer A, Katz J, Quigley H, Ezrine S. Socioeconomic status and visual impairment among urban Americans. Arch Ophthalmol 1991; 109(5): 637-641.

8 Abou-Gareeb I, Lewallen S, Bassett K, Courtright P. Gender and blindness: a meta-analysis of population-based prevalence surveys. Ophthalmic Epidemiol 2001; 8(1): 39-56.

9 Schaumberg DA, Nichols KK. The global sex disparity in blindness and visual impairment. Optom Vis Sci 2006; 83(10): 700-701.

10 Yao Y, Shao J, Sun W, Zhu J, Hong Fu D, Guan H et al. Prevalence of blindness and causes of visual impairment among adults aged 50 years or above in southern. Jiangsu Province of China. Pak J Med Sci 2013; 29(5): 1203-1207.

11 Zheng Y, Lavanya R, Wu R, Wong WL, Wang JJ, Mitchell P et al. Prevalence and causes of visual impairment and blindness in an urban Indian population: the Singapore Indian Eye Study. Ophthalmology 2011; 118(9): 1798-1804.

12 Sung KR, Wollstein G, Bilonick RA, Townsend KA, Ishikawa $\mathrm{H}$, Kagemann $\mathrm{L}$ et al. Effects of age on optical coherence tomography measurements of healthy retinal nerve fiber layer, macula, and optic nerve head. Ophthalmology 2009; 116(6): 1119-1124.

13 Klein BE, Klein R, Linton KL. Prevalence of age-related lens opacities in a population: the Beaver Dam Eye Study. Ophthalmology 1992; 99(4): 546-552.

14 Group EDPR. The prevalence of diabetic retinopathy among adults in the United States. Arch Ophthalmol 2004; 122(4): 552.

15 World Health Organization. Visual impairment and blindness. Available at: http://www.who.int/mediacentre/ factsheets/fs282/en/.

16 Naidoo K. Poverty and blindness in Africa. Clin Exp Optom 2007; 90(6): 415-421.

17 Gilbert CE, Shah S, Jadoon M, Bourne R, Dineen B, Khan MA et al. Poverty and blindness in Pakistan: results from the Pakistan national blindness and visual impairment survey. Brit Med J 2008; 336(7634): 29-32.

18 Resnikoff S, Pascolini D, Etya'ale D, Kocur I, Pararajasegaram R, Pokharel GP et al. Global data on visual impairment in the year 2002. Bull World Health Organ 2004; 82(11): 844-851.

19 World Health Organisation. Priority eye diseases. Available at: http://www.who.int/blindness/causes/priority/en/ index1.html.

20 Dandona L, Dandona R, Srinivas M, Giridhar P, Vilas K, Prasad MN et al. Blindness in the Indian state of Andhra Pradesh. Invest Ophthalmol Vis Sci 2001; 42(5): 908-916.

21 Evans T. Socioeconomic consequences of blinding onchocerciasis in west Africa. Bull World Health Organ 1995; 73(4): 495.

22 Zhu T, Ma J, Li Y, Zhang Z. Association between retinal neuronal degeneration and visual function impairment in type 2 diabetic patients without diabetic retinopathy. $S c i$ China Life Sci 2015; 58(6): 550-555.

23 VanNewkirk MR, Weih L, McCarty CA, Taylor HR. Causespecific prevalence of bilateral visual impairment in Victoria,
Australia: the Visual Impairment Project. Ophthalmology 2001; 108(5): 960-967.

24 He M, Zeng J, Liu Y, Xu J, Pokharel GP, Ellwein LB. Refractive error and visual impairment in urban children in southern China. Invest Ophthalmol Vis Sci 2004; 45(3): 793-799.

25 World Health Organisation. What is a refractive error?. Available at: http://www.who.int/features/qa/45/en/.

26 Resnikoff S, Pascolini D, Mariotti SP, Pokharel GP. Global magnitude of visual impairment caused by uncorrected refractive errors in 2004. Bull World Health Organ 2008; 86(1): 63-70.

27 Marmamula S, Keeffe JE, Raman U, Rao GN. Populationbased cross-sectional study of barriers to utilisation of refraction services in South India: Rapid Assessment of Refractive Errors (RARE) Study. BMJ Open 2011; 1(1): e000172.

28 Dana MR, Tielsch JM, Enger C, Joyce E, Santoli JM, Taylor HR. Visual impairment in a rural Appalachian community: prevalence and causes. JAMA 1990; 264(18): 2400-2405.

29 Gwatkin DR, Wagstaff A, Yazbeck A. Reaching the poor with health, nutrition, and population services: what works, what doesn't, and why: World Bank Publications 2005.

30 Dandona R, Dandona L. Refractive error blindness. Bull World Health Organ 2001; 79(3): 237-243.

31 Kedir J, Girma A. Prevalence of refractive error and visual impairment among rural school-age children of Goro District, Gurage Zone, Ethiopia. Ethiop J Health Sci 2014; 24(4): 353-358.

32 Shaw JE, Sicree RA, Zimmet PZ. Global estimates of the prevalence of diabetes for 2010 and 2030. Diabetes Res Clin Pract 2010; 87(1): 4-14.

33 Yau JW, Rogers SL, Kawasaki R, Lamoureux EL, Kowalski JW, Bek T et al. Global prevalence and major risk factors of diabetic retinopathy. Diabetes Care 2012; 35(3): 556-564.

34 Hautala N, Aikkila R, Korpelainen J, Keskitalo A, Kurikka A, Falck A et al. Marked reductions in visual impairment due to diabetic retinopathy achieved by efficient screening and timely treatment. Acta Ophthalmol 2014; 92(6): 582-587.

35 Li Z, Cui H, Liu P, Zhang L, Yang H. Prevalence and causes of blindness and visual impairment among the elderly in rural southern Harbin, China. Ophthalmic Epidemiol 2008; 15(5): 334-338.

36 Michon JJ, Lau J, Chan WS, Ellwein LB. Prevalence of visual impairment, blindness, and cataract surgery in the Hong Kong elderly. Br J Ophthalmol 2002; 86(2): 133-139.

37 Oye JE, Kuper H, Dineen B, Befidi-Mengue R, Foster A. Prevalence and causes of blindness and visual impairment in Muyuka: a rural health district in South West Province, Cameroon. Br J Ophthalmol 2006; 90(5): 538-542.

38 Oye JE, Kuper H. Prevalence and causes of blindness and visual impairment in Limbe urban area, South West Province, Cameroon. Br J Ophthalmol 2007; 91(11): 1435-1439.

39 Yekta A, Hashemi H, Ostadimoghaddam H, Shafaee S, Norouzirad R, Radaye-Moghaddam S et al. Prevalence and causes of visual impairment among the elderly of Sari, 2011. Iran J Ophthalmol 2013; 25(4): 262-269.

40 Fotouhi A, Hashemi H, Mohammad K, Jalali KH, Tehran Eye $\mathrm{S}$. The prevalence and causes of visual impairment in Tehran: the Tehran Eye Study. Br J Ophthalmol 2004; 88(6): 740-745. 
41 Liu H, Zhao JL, Lu H, Li FR, Mao J, Ellwein LB et al. [Prevalence of blindness and moderate and severe visual impairment among adults aged 50 years or above in the Shunyi District of Beijing: The China Nine-Province Survey]. Zhonghua Yan Ke Za Zhi 2012; 48(3): 199-204

$42 \mathrm{Li} \mathrm{T}, \mathrm{Du} \mathrm{L}, \mathrm{Du} \mathrm{L}$. Prevalence and causes of visual impairment and blindness in Shanxi Province, China. Ophthalmic Epidemiol 2015; 22(4): 239-245.

43 Gupta N, Vashist P, Malhotra S, Senjam SS, Misra V, Bhardwaj A. Rapid assessment of visual impairment in urban population of Delhi, India. PLoS One 2015; 10(4): e0124206.

44 Cheng F, Shan L, Song W, Fan P, Yuan H. Distance- and near-visual impairment in rural Chinese adults in Kailu, Inner Mongolia. Acta Ophthalmol 2015; 94(4): 407-413.

45 Adhikari S, Shrestha MK, Adhikari K, Maharjan N, Shrestha UD. Causes of visual impairment and blindness in children in three ecological regions of Nepal: Nepal Pediatric Ocular Diseases Study. Clin Ophthalmol 2015; 9: 1543-1547.

46 Zhang L, Cui H, Zhao J, Ellwein LB, Li Z, Li M et al. Prevalence of blindness and moderate and severe visual impairment among adults aged 50 years or above in Shuangcheng City of Heilongjiang Province: the China NineProvince Survey. Zhonghua Yan Ke Za Zhi 2014; 50(3): 173-178.

47 Singh N, Eeda SS, Gudapati BK, Reddy S, Kanade P, Shantha GP et al. Prevalence and causes of blindness and visual impairment and their associated risk factors, in three tribal areas of Andhra Pradesh, India. PLoS One 2014; 9(7): e100644.

48 Patil S, Gogate P, Vora S, Ainapure S, Hingane RN, Kulkarni AN et al. Prevalence, causes of blindness, visual impairment and cataract surgical services in Sindhudurg district on the western coastal strip of India. Indian J Ophthalmol 2014; 62(2): 240-245.
49 Mousa A, Courtright P, Kazanjian A, Bassett K. Prevalence of visual impairment and blindness in Upper Egypt: a gender-based perspective. Ophthalmic Epidemiol 2014; 21(3): 190-196.

50 Minderhoud J, Mans DR, Pawiroredjo JC, Pameijer JH, Saeed P, Moll AC. Causes of blindness and visual impairment in the interior Maroon population in the Republic of Suriname. Acta Ophthalmol 2014; 92(2): e162-e164.

51 Ge J, He M, Zhao J, Fang M, Ellwein LB, He N et al. Prevalence of blindness and moderate and severe visual impairment among adults aged 50 years or above in Yangxi County of Guangdong Province: the China Nine-Province Survey. Zhonghua Yan Ke Za Zhi 2014; 50(3): 167-172.

52 Yin ZQ, Zhao JL, Li PH, Ellwein Lb, Song SF, Li FL et al. Prevalence and causes of blindness and moderate and severe visual impairment among adults aged 50 years or above in Yongchuan District of Chongqing City: the China NineProvince survey. Zhonghua Yan Ke Za Zhi 2013; 49(9): 777-782.

53 Rabiu MM, Jenf M, Fituri S, Choudhury A, Agbabiaka I, Mousa A. Prevalence and causes of visual impairment and blindness, cataract surgical coverage and outcomes of cataract surgery in Libya. Ophthalmic Epidemiol 2013; 20(1): 26-32.

54 Nangia V, Jonas JB, Gupta R, Khare A, Sinha A. Visual impairment and blindness in rural central India: the Central India Eye and Medical Study. Acta Ophthalmol 2013; 91(5): 483-486.

55 Gunnlaugsdottir E, Arnarsson AM, Jonasson F. Visual impairment and blindness in Icelanders aged 50 years and older-the Reykjavik Eye Study. Laeknabladid 2013; 99(3): 123-127.

56 Hashemi H, Khabazkhoob M, Emamian M, Shariati M, Fotouhi A. Visual impairment in the 40-to 64-year-old population of Shahroud, Iran. Eye 2012; 26(8): 1071-1077. 